\title{
The Impact of New Technology on Sustainable Development
}

\author{
Jozef Habanik, Adriana Grencikova, Karol Krajco
}

\author{
A. Dubcek University of Trencin \\ Studentska 3, 91150 Trencin, Slovakia \\ E-mail.jozef.habanik@tnuni.sk, adriana.grencikova@tnuni.sk,karol.krajco@tnuni.sk
}

cross $^{\text {ref }}$ http://dx.doi.org/10.5755/j01.ee.30.1.20776

\begin{abstract}
The study addresses the aspects of sustainable economic development in terms of Industry 4.0. The fourth industrial revolution is built on digitalization of manufacturing processes, gathering and analysing data across machines and transformation of enterprises into smart and sustainable ones. This manufacturing revolution will bring along significant changes in labour markets. The Slovak economy focuses on industrial production based on cheap labour. In terms of Industry 4.0, the pools of low-skilled workers will no longer be needed. Even today, digital skills and competences are needed for employment. Thus, attention needs to be paid to the need to develop digital skills in order to achieve sustainable economic and social development of countries and regions. The purpose of the paper is to analyse the selected indicators of sustainable development and the effects of Industry 4.0 on their development in the Slovak Republic. The analysis of sustainable development indicators within the framework of Industry 4.0 makes the paper original. The issue has not been treated from this perspective in the Slovak Republic. Thus, new opportunities are opened up to examine social and economic effects of Industry 4.0. Several scientific disciplines tackled the issue from their own perspectives whereas associations of different kinds were not investigated. Basic mathematical and statistical methods (timelines, comparative statistics), analysis of materials, publications, governmental concepts and the EU decisions on the issue have been employed. The data were drawn from the Statistical Office of the Slovak Republic, Ministry of Economy, OECD and EUROSTAT. The authors attempted to identify new opportunities for achieving long-term competitiveness of the Slovak economy and sustainable social development. Several recommendations have been made mainly to the education sector which is deemed for driving innovation.
\end{abstract}

Keywords: Smart Enterprises; Educational System; Labour Market; Digitization; Industry 4.0.

\section{Introduction}

Different views on resources and economic growth have been put forward in the course of human history. The basic model of economic growth says that the factors of production are vital for economic growth. Capital refers to anything used to produce goods. Capital is not only money itself (Fischer et al., 1988) in addition, capital includes machinery, equipment, buildings, know-how, etc. Aggregate production function can be written as GDP $=\mathrm{f}$ $(\mathrm{K}, \mathrm{L})$, where $\mathrm{K}$ is used to represent capital and $\mathrm{L}$ to represent labour (Byrns \& Stone, 1989). Thus, GDP growth depends on capital growth and labour force growth. Up to now, capital accumulation and population growth have triggered economic growth. Industry 4.0, however, will decrease the demand for low-skilled workers. There are several other factors affecting the productivity of these factors, such as technical progress, innovation, economies of scale. The economic growth of countries depends on various factors, they can include demographic trends, political system, legislation, culture, trade relations, natural conditions, etc. (Masarova, 2015).

It was the theory of mercantilism which first addressed the opportunities of economic growth. According to this theory, money was not only a medium for making transactions. Money was seen as the source of liquidity correlated with future economic growth (Samuelson \& Nordhaus, 2007). According to Samuelson and Nordhaus, mercantilism was based on the idea that the main sources of wealth were precious metals, colonial expansion and positive balance of trade. Physiocrats asserted that land and agriculture are the sources of all wealth (Lisy, 2003). For Quesnay, the remaining sectors of economy were sterile as they were not producing new products, but only giving new shapes to existing raw materials (Koisova et al., 2003). Classical economists used the concept of invisible hand coined by Adam Smith (2008). They saw labour and productivity as the source of all wealth. The proponents of classical economics believed that the division of labour, improvement of employee skills can lead to higher productivity. Another important source of economic growth of countries is the accumulation of capital. David Ricardo (2004), a follower of Adam Smith, argued that foreign trade had been the main source of economic growth. Thomas Malthus (2017) identified the obstacles to the improvement of society, such as population growth and food resources. In his theory of economic development, Joseph Schumpeter (1983) described the adaptive response of economies to the increase of population or sectoral changes by the expansion of existing factors. When the forces of change act outside of the range of existing practice, a creative response is used by economies. Currently, an increase in productivity and productive capacity are considered to be the major factors of economic growth (Masarova, 2015). The key factors that determine productivity include physical capital, human capital, natural wealth, technological change and innovation. 
Kordos and Karbach (2014) argued that they had been vital not only for creating more jobs, building a greener society and improving quality of life, but also for maintaining companies' competitiveness on the global market and the enhancement of states'/economies' competitiveness within the international economic system. Technology has become internationalized.

In the 1970s, the question of sustainable development was at the forefront. Economies focused only on uncontrolled economic growth under conditions of scarce resources, and this represented a high risk for the future. The first definition for sustainability appeared in 1972 in The Ecologist. In the very same year, the UN Conference on the Human Environment was held in Stockholm. The conference was devoted to sustainable development in society. In 1983, the United Nations World Commission on Environment and Development (WCED) was established. In 1987, the report of the World Commission on Environment and Development entitled Our Common Future which the Commission submitted for approval to the United Nations General Assembly offered new approaches to environment and development. The report included the definition of sustainable development as the development which meets the needs of today without compromising the ability of next generations to meet their own needs.

In 1992, the United Nations Commission on Sustainable Development (CSD) was set up to monitor the implementation of documents adopted at the United Nations Conference on Environment and Development (UNICED) held in Rio de Janeiro in the same year. At the fourth session, the CSD mandated the set of 132 indicators of sustainable development. The collection of indicators and methodology sheets is commonly referred to as the "blue book". In the book, 76 indicators refer to the social, economic and institutional dimensions of sustainable development and 56 cover the environmental dimensions of sustainable development. The basic principles of sustainable development are as follows:

1. the consumption rate of renewable natural resources should not exceed the rate of their recovery;

2. the use of non-renewable resources in such a way that their consumption rate grows as fast as in the case of renewable substitutes;

3. the generation of waste, including emissions, only to the extent that it is absorbed by the environment without adverse effects on human health and which does not endanger other forms of life.

Today, the most used energy sources include coal, natural gas, and nuclear fuel. In order to essentially change the energy production manner, it is not enough to just divert resources for this purpose, because that requires a lot of financial and human resources. Transformation process can relieve companies with concentrated resources for general purpose (Navickas et al., 2017).

In 2000, world leaders set out a series of time-bound targets with a deadline of 2015 that have become known as the Millennium Development Goals. These goals have been partially met. The Rio+20 Sustainable Development Conference established an intergovernmental process to prepare sustainable targets for 2012. A 30-member open working group (OWG) of the General Assembly was tasked to prepare a proposal on the sustainable development goals.
The OWG proposed 17 sustainable development goals. The UN Task Team published its first report titled Realizing the Future We Want for All. The report outlined the vision of the UN system on the global development agenda beyond 2015. Thus, four key dimensions were identified: inclusive social development, inclusive economic development, environmental sustainability, peace and security. Polanyi (1957) and Max-Neef (2014) argued that sustainability had been examined by many specialists and institutions. At the UN Sustainable Development summit of 2015, the new 2030 Agenda sustainable development was adopted by world leaders. The main challenges include: coordinating local, national and global responses (Kanie \& Bierman, 2017; Bowen et al., 2017), avoiding negative consequences from responses to goals (or parts there-of) in isolation (Gao \& Bryan, 2017; Nilsson, 2017; Nielson \& Girggs \& Visbeck, 2016), accessing information and resources to understand the goals and how to respond, and monitoring, evaluating and assessments of progress at all scales in particular sectors (Bhaduri et al., 2016; Haski-Leventhal, 2015; Nilsson et al., 2013).

It is possible to assume that economic development and trends on the labour market (and unemployment rate) did not simply and linearly mirror the pace of economic development under these difficult economic, social and political conditions, and causal relationship between economic development and unemployment level is much more complex according to Vojtovic (2013). The current workforce must adapt and train its skills and knowledge for the changes of Industry 4.0, or otherwise encounter difficulties in meeting the requirements of new jobs (Longo, et al., 2017).

The Industry 4.0 is a strategic initiative introduced by the German Government. The initiative was first presented at the Hannover Fair in 2011 (Rojko, 2017). The full document was presented at the Hannover Fair in 2013, and the government allocated $€ 50$ million to the Industry 4.0 program for a period of 3 years. Thus, the German government endeavoured to sustain competitiveness without the need to shift their factories to poorer countries with cheaper labour. In the United Stated, the Smart Manufacturing Leadership Coalition (SMLC) has been founded. The SMLC is an organization comprised of industries, suppliers, technology companies, manufacturing consortia, universities, government agencies and laboratories. The SMLC and Industry 4.0 handle similar problems. In the European Union, discussions on the challenges associated with the fourth industrial revolution are also held by practitioners and academics. They are discussing what specific measures are to be taken in order to digitize the European industry and catch up with the competitiveness of the USA, China, and Japan. These initiatives do not only address current and future challenges but also offer ample opportunities to industry, trade and economy. That is why, the conception of Smart Industry for Slovakia has been approved by the Slovak Government. Leading figures from public sector, industry and academia are engaged in the Smart Industry program. The program aims to boost innovation in industry with technological advances and help Slovakia adapt to innovation-related changes. Industry 4.0 changes the existing industry structures in Slovakia. Thus, automation and digitization of 
manufacturing, digitization of control systems, and the use of communications networks to ensure interoperability and flexibility in manufacturing are among the priorities laid down in the Smart Industry program. Since the Internet is becoming an integral part of industrial control systems, huge amounts of data can be exchanged and functionally analysed. In addition, Industry 4.0 promises to offer virtual process simulation, cloud environments, augmented reality of autonomous devices and 3D printing.

In smart factories, the Internet of Things systems link robots and process control systems together. Moreover, hardware, software and technological processes are integrated, and thus made more customizable, independent and decentralized. This way, a product time to market is improved. Continuous interaction in digital factories and the integration of product lifecycle data in supply chain processes can save resources, offer better services and ensure continuous improvement. Digital factories will allow to maximise profit, involve end-users in manufacturing, and devise better service models.

Smart industry is characterized by regular increases in innovation. In addition, it is an important driver of applied science and research in Slovakia and the improvement of workplaces for scientists. Smart industry also focuses on smart raw material and resource solutions in line with the sustainable development goals. Humans will perform creative activities whereas physically demanding work will be shifted from people to machines and systems, and more decent working conditions will be created for employees (Strunz \& Vojtovic, 2014).

\section{Data and Methodology}

The paper attempted to analyse the impacts on the Slovak labour market, education system and social areas. As Slovakia is a diversified economy and effects will vary widely by regions. The drivers of change are multiple, and advances in cloud computing, big data, the Internet of things, artificial intelligence, machine learning, smart systems and robotics are just a few ones worth mentioning. We consider the elimination of a vast number of jobs to be the most serious threat for industry and economy (54\% of jobs in industry according to some reports).

Secondary literary foreign and domestic sources were applied in the Introduction section. Additional data were taken from institutions, such as the European Statistical Office, OECD and Statistical Office of the Slovak Republic. The research paper aimed to analyse a few selected indicators of sustainable development in the Slovak Republic. The following economic, social and environmental indicators were monitored: GDP, employment, unemployment, employment by industry, employment in high- and medium-high technology manufacturing sectors and knowledge-intensive service sectors, energy efficiency and pollution. To support the assumptions made, the share of employment by educational attainment was monitored. Next, the data related to the selected indicators of sustainable development and growth were analysed. The estimation of trend function was employed to analyse time series. The linear function of this trend was used because the values of the monitored indicators oscillate around the line. Thus, the following dependence of the values of the monitored indicator was assumed $y t=\beta 0+\beta 1 \mathrm{t}$, where $\mathrm{t}$ is a time independent variable $(\mathrm{t}=1,2, \ldots, \mathrm{n})$. In addition to the above methods, general scientific and special research methods were used, such as comparative analysis, synthesis, comparison, deduction and induction. Descriptive statistics was selected as the data available usually go only 10 years back. That is why, it was not possible to use other methods that would lead to more relevant conclusions. The phenomena occurring in certain processes and time were compared. The development of nominal and real convergence of the respective indicator in the Slovak Republic to the EU28 was monitored. The economic convergence of the Slovak Republic towards the EU28 was monitored. Then, the development of disparities in real convergence was pointed to. The convergence of nominal indicators in nominal convergence was also examined.

The present paper addressed sustainable development in the Slovak Republic (SR) as member state of the European Union. Therefore, all related documents follow the EU legislation on sustainable development. Under the Maastricht Treaty, the environmental protection requirements were integrated into definition and implementation of the European Union policies and activities, mainly with a view of promoting sustainable development. Additional details were discussed at the EU summit in Cardiff in 1998. The EU Sustainable Development Strategy was adopted in May 2001. The Strategy aimed to ensure a high level of environmental protection, social justice and cohesion, economic prosperity and active global support for sustainable development. The following indicators have been identified in the Strategy: economic development, poverty and social exclusion, population aging, public health, climate change and energy, patterns of production and consumption, management of natural resources, transport, good governance, as well as global partnership. EU targets correspond with the $17 \mathrm{UN}$ targets set out in AGENDA2030 in 2015. Eurostat published the indicators for monitoring sustainable targets in the EU upon the EC approval in May 2017. EU SDG indicator set includes 100 different indicators allocated to the 17 SDGs; 41 of these are multipurpose indicators (MPI), used to monitor more than one goal. These 17 sustainable development goals are as follows: poverty, agriculture and nutrition, health, education, gender equality, water, energy, economy and labour, infrastructure and innovation, inequality, cities, consumption and production, climate, oceans, ecosystems, institutions, and global partnership.

Sustainable development in the Slovak Republic is legally defined by $\S 6$ of the Act No. 17/1992 Coll. on the Environment. Thus, sustainable development is defined as "the one meeting the needs of the present and future generations, while not diminishing the quality of the present environment and preserving the natural functions of ecosystems." The National Sustainable Development Strategy (2001) defines sustainable development as a targeted, long-term, comprehensive and synergic process that affects the conditions and all aspects of life (cultural, social, economic, environmental, and institutional) at all levels (local, regional, global) and towards such a functional model of a particular community (local and regional community, country, international community) that satisfies the biological, material, spiritual and social needs and 
interests of the people, eliminates or significantly reduces interference that endangers, damages or destroys conditions and forms of life, does not burden the country, rationalizes resources and protects cultural and natural heritage. State performance is given by the national and regional economic performance. The government should make efficient use of all resources to ensure high standards of living and economic growth as argued by Masarova (2014).

The present paper aimed to analyse only a few selected indicators of sustainable development in the Slovak Republic. The development of indicators towards the indicator average values in the EU28 was compared.

\section{Empirical Results}

The basic indicator of socioeconomic development is the real gross domestic product per capita. The Slovak Republic had positive growth throughout the reporting period except 2009 , when there was a $5.56 \%$ drop due to the global financial and economic crisis (EU28: $-4,8 \%$ ). EU28 economic growth was zero in 2008. The economic growth in the Slovak Republic grew by $5.88 \%$ in the same year. In the monitored period, the real GDP in the SR increased by $82.5 \%$ in 2016 compared to 2001, while this increase amounted to only $15.38 \%$ in EU28. In 2001, the real GDP per capita was $34.19 \%$ in EU28, whereas it was $54.07 \%$ at the end of the monitored period in 2016.

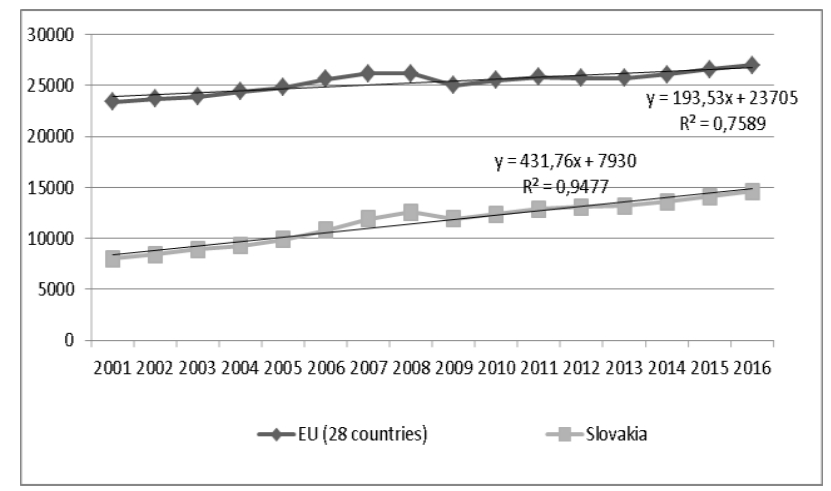

Figure 1. Development of real GDP and its linear trend

Source: EUROSTAT, authors' own calculations

Figure 1 shows that the linear development trend is growing with a high confidence level of $95.64 \%$ (confidence value $\mathrm{r} 2=0.9564$ ). A high confidence level above $90 \%$ was also found by the trend equations polynomial, exponential and logarithmic. The difference between the SR and EU28 values shows a decreasing trend. It would take Slovakia 53 years to catch up with the EU28. Theoretically, the indicator value was approximately $€$ 37,860 according to the linear trend.

It can be seen from Table 1 that the employment rate in the Slovak Republic is below the EU average in the category of persons with lower secondary education. The average employment rate in this category was $54.17 \%$ in the EU whereas it was $29.4 \%$ in the Slovak Republic over the monitored period of 15 years. There was no significant change in employment and the rate fell by 1.2 percentage point over the base year of 2002 in the EU28. An increasing trend can be observed in the Slovak Republic, the employment rate increased by 8.1 percentage point. In the category of secondary and post-secondary education, no significant differences between the SR and EU average were identified. In the Slovak Republic, an increase by 5.2 percentage point was established even in this category. IN the EU, the employment rate increased by 2.4 percentage point. The average employment rate in the monitored period was $70.12 \%$ in the EU and $67.94 \%$ in the SR.

Table 1

\section{Employment Rates by Educational Attainment Level (\%)}

\begin{tabular}{|l|l|l|l|l|l|l|l|l|l|l|l|l|l|l|}
\hline 2002 & 2003 & 2004 & 2005 & 2006 & 2007 & 2008 & 2009 & 2010 & 2011 & 2012 & 2013 & 2014 & 2015 & 2016 \\
\hline
\end{tabular}

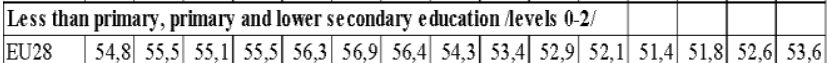
\begin{tabular}{|l|l|l|l|l|l|l|l|l|l|l|l|l|l|l|l|}
\hline Slovakia & 27,8 & 28,3 & 25,6 & 25,3 & 27,4 & 27,9 & 31 & 29 & 28,6 & 29,6 & 29,5 & 30,3 & 31,6 & 33,2 & 35,9 \\
\hline
\end{tabular} Upper secondary and post-secondary non-tertiary education levels 3 and 4 / \begin{tabular}{|l|r|r|r|r|r|r|r|r|r|r|r|r|r|r|r|}
\hline EU28 & 69,2 & 69,1 & 69 & 69,5 & 70,5 & 71,4 & 71,8 & 70,3 & 69,9 & 69,8 & 69,6 & 69,4 & 70,1 & 70,7 & 71,6 \\
\hline
\end{tabular} \begin{tabular}{|l|l|l|l|l|l|l|l|l|l|l|l|l|l|l|l|}
\hline Slovakia & 66,3 & 67,8 & 67 & 67,4 & 68,4 & 69,9 & 71 & 67,9 & 65,9 & 66,2 & 66,5 & 66,4 & 67,6 & 69,3 & 71,5 \\
\hline
\end{tabular}

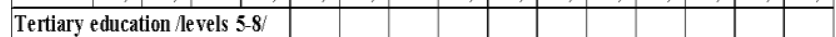
\begin{tabular}{|l|r|l|l|l|l|l|l|l|l|l|l|l|l|l|l|}
\hline EU28 & 82,7 & 82,6 & 82,6 & 82,7 & 83,2 & 83,8 & 83,8 & 82,9 & 82,4 & 82,1 & 81,9 & 81,7 & 82,1 & 82,7 & 83,4 \\
\hline
\end{tabular} \begin{tabular}{|l|l|l|l|l|l|l|l|l|l|l|l|l|l|l|l|l|l|}
\hline Slovakia & 85,8 & 86,7 & 82,3 & 83,2 & 83,9 & 83,1 & 83,8 & 80,3 & 78 & 76,7 & 74,8 & 74,7 & 75,6 & 76,5 & 77,3 \\
\hline
\end{tabular}

Source: EUROSTAT, authors' own elaboration

No significant difference was found between the average employment rate in the SR $(80.1 \%)$ and the EU28 $(82.7 \%)$ in the category of employees with tertiary education. A significant drop in the employment rates by 8.5 percentage points between 2002 and the last year of the reference period was found in this category in the SR. It follows from the above table that during the monitored period, an average of $80.18 \%$ of the population with tertiary education were employed. In the below lower secondary education categories, an increase was seen. It is caused by the growth of manufacturing industry with a high demand for manual labour.

The most numerous category are the employees with secondary and post-secondary educational attainment. There is a marked difference between the SR and the EU28 between the category of employees with lower and upper secondary education, with an average of $20.41 \%$ in the EU and only $4.15 \%$ in the SR. On the contrary, the category of employees with secondary education reached the average of $75.43 \%$ in the SR and $49 \%$ in the EU.

In the category of population with tertiary education, there was an upward trend both in the Slovak Republic and in the EU. In the Slovak Republic, the identified level was lower by approximately 10 percentage points compared to the EU over the whole monitored period.

Table 2

Overall Unemployment and Employment in the SR (Thousand Persons) and its Change

\begin{tabular}{|c|c|c|c|c|c|c|c|c|c|}
\hline GEOTIME & 2008 & 2009 & 2010 & 2011 & 2012 & 2013 & 2014 & 2015 & 2016 \\
\hline Ev28 & 16751 & 21300 & 22989 & 23124 & 25266 & 26304 & 24807 & 22879 & 20917 \\
\hline unemployment $S R$ & 254 & 321 & 306 & 363 & 378 & 306 & 359 & 314 & 267 \\
\hline annual change in SR & $x$ & 67 & 65 & -23 & 15 & 8 & -27 & 45 & 47 \\
\hline change of unemployed in SR ( $\mathrm{s}, \mathrm{s}$ & $x$ & 26 & 20 & -6 & 4 & 2 & .7 & .13 & -15 \\
\hline Ev28 & 218924,1 & 214981,3 & 212089,4 & 212033,0 & 211351,1 & 210783,6 & 213420,7 & 215709,7 & 218843,2 \\
\hline employment SR & 2423,4 & 2356,6 & 2307,2 & 2303,2 & 2317,2 & 2317,7 & 2349,2 & 2405,1 & 2471,7 \\
\hline annual change & $x$ & $.66,8$ & $.49,4$ & $-4,0$ & 14,0 & 0,5 & 31,5 & 55,9 & 66,0 \\
\hline change of employed in SR $(\mathrm{h})$ & $x$ & $-2,8$ & $-2,1$ & $-0,2$ & 0,6 & 0,0 & 1,4 & 2,4 & 2,8 \\
\hline
\end{tabular}

Source: EUROSTAT, authors' own calculations

To make the table above complete, employment and unemployment rates from 2001 to 2016 were listed. The 
average value of the employment rate was $65.72 \%$ in Slovakia and $68.64 \%$ in the EU. The development trend was the same for both Slovakia and the EU. Even though the unemployment rate in the Slovak Republic increased by 6.3 percentage points and in the EU by 4.2 percentage points compared to the starting year, a positive development of employment in the Slovak Republic can be inferred.

Despite the favourable development of unemployment rate in the last 3 years of the monitored period in the Slovak Republic, the development of unemployment in Slovak Republic was unfavourable and well above the EU average. The average unemployment rate reached $14.2 \%$ in the SR compared to $9.09 \%$ in the EU in the monitored period.

The following figure shows the development of the number of employed and unemployed persons in the SR. The average number of unemployed people was 336 thousand in the monitored years. The difference in the number of unemployed in 2008 (254 thousand) compared to 2016 (267 thousand) represents an increase by $5.1 \%$. This may seem insignificant. It should, however, be born in mind that during the monitored period the number of unemployed people reached 386,000 in 2013, an increase by $51.97 \%$ compared to 2008. The average number of those in employment was 2361 thousand persons. Despite the unfavourable growth of unemployment in the monitored period, a drop in employment can be seen only in the three years from 2009-2011. The employment rate has been rising since 2012. The number of employed in 2016 compared to 2008 rose by $1.99 \%$.

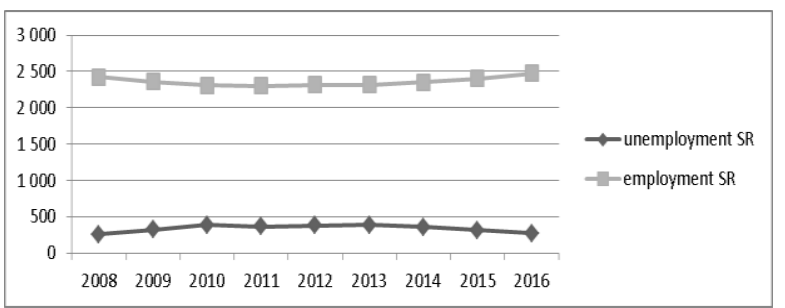

Figure 2. Development of Employment and Unemployment Rates in the SR (Thousand Persons)

Source: (EUROSTAT, authors' own elaboration)

The same applies for both the employed and unemployed. The changing numbers of those employed and unemployed are shown in Figure 3. In the countries of Central and Eastern Europe it is a commonly accepted conclusion that a solution for a problem with unemployment is mainly connected with the inflow of direct foreign investments and economic growth (Koisova \& Masarova, 2012) or (Sileika \& Andriusaitiene, 2006).

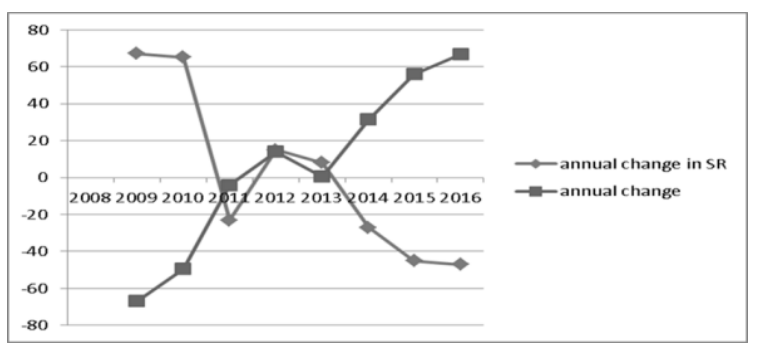

Figure 3. Annual change in numbers of those unemployed and employed in the SR (thousand persons)

Source: (EUROSTAT, authors' own elaboration)
Employment in high- and medium-high technology manufacturing sectors and knowledge-intensive service sectors (\% of total employment) was on the rise during the monitored period. The Slovak Republic lagged behind the EU28 average by $3.1 \%$ in 2008. The Slovak Republic almost reached the EU28 average with the difference of $1.4 \%$ last year. Employees in this group accounted for $44.4 \%$ of total employment. The positive development trend is obvious and the EU expects growth in the coming years

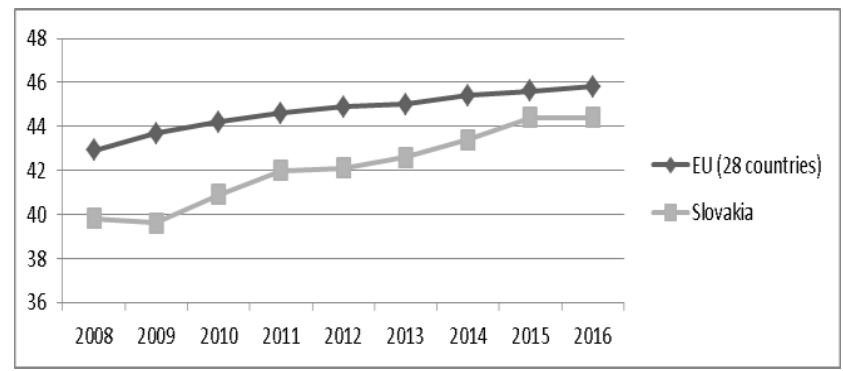

Figure 4. Employment in High- and Medium-High Technology Manufacturing Sectors and Knowledge-Intensive Service Sectors (\% of Total Employment)

Source: EUROSTAT, authors' own elaboration

The value of patent activity intensity indicator was very low in the Slovak Republic. 106.31 patents per million inhabitants were filed from within the EU28 in 2000 compared to only 2.08 patents filed by the Slovak Republic. The trend of the growth of patents $(4.51 \%)$ is also unsatisfactory. The number of patents filed was 9.39 in the SR and 111.97 in the EU28 per million inhabitants.

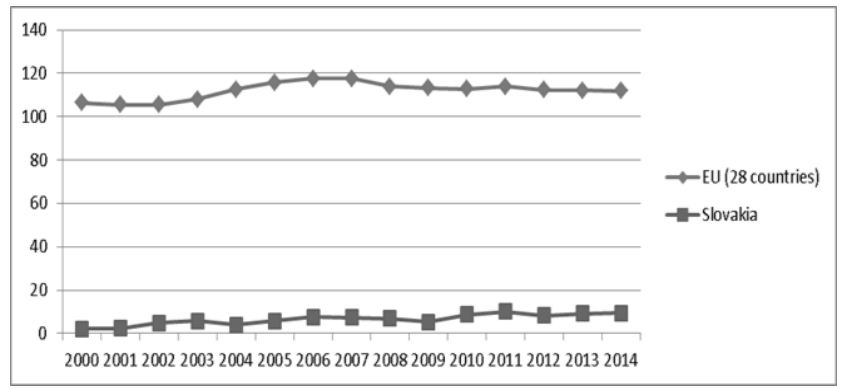

Figure 5. Patent Applications to the European Patent Office (per Million Inhabitants)

Source: (EPO, authors' own elaboration)

With regard to final energy consumption, the consumption was $90.1 \%$ compared to the base year of 2005 . The development of final energy consumption follows the developments in the EU28. The EU28 has the consumption level of $92.9 \%$ in 2016 compared to 2005. From the perspective of long-term sustainable development, it is important to highlight the evolution of the share of renewable energy in gross final energy consumption. The Slovak Republic increased the share from $6.4 \%$ to $12 \%$ in the monitored period. The share, however, increased also in the EU28 (from $8.5 \%$ in 2004 to $17 \%$ in 2016). 


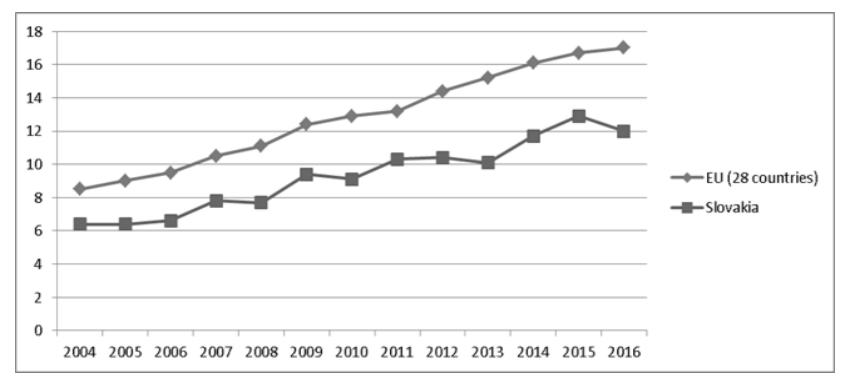

Figure 6. Share of Renewable Energy in Gross Final Energy Consumption

Source: (EUROSTAT, authors' own elaboration)

With regard to the sustainable development goal of clean water and sanitation, the data are alike for Slovakia and EU28. Table 3 shows the pollution of rivers and groundwater by years 2000 through 2012. The Slovak Republic managed to reduce the pollution in the monitored period. The level of phosphates was above the EU average, yet Slovakia recorded a $36.55 \%$ decrease in phosphate levels The EU data are aggregate changing according to the context.

Table 3

Clean Water and Sanitation

\begin{tabular}{|l|c|c|c|c|c|c|c|c|c|c|c|c|c|}
\hline \multicolumn{10}{|c|}{ Biochem ical oxygen demand in nivers (mg 02 per lite) } \\
\hline geoltime & 2000 & 2001 & 2002 & 2003 & 2004 & 2005 & 2006 & 2007 & 2008 & 2009 & 2010 & 2011 & 2012 \\
\hline European Union & 2,95 & 2,89 & 2,75 & 2,68 & 2,38 & 2,32 & 2,3 & 2,36 & 2,21 & 2,16 & 2,15 & 2,12 & 2,19 \\
\hline Slovakia & 3,28 & 3,02 & 3,08 & 2,69 & 2,32 & 2,19 & 2,07 & 2,23 & 2,1 & 1,86 & 2,19 & 2,25 & 2,2 \\
\hline \multicolumn{10}{|c|}{ Nitrate in groundwater (mg N03 per litre) } \\
\hline European Union & 19,1 & 19,2 & 19 & 19,2 & 19,3 & 19,9 & 20,4 & 20,4 & 19,7 & 19,2 & 19,3 & 19 & 19,1 \\
\hline Slovakia & 19,9 & 18,8 & 15,9 & 14,3 & 17,7 & 18,3 & 18,3 & 17,7 & 21,5 & 20,4 & 20,9 & 16,6 & 16,4 \\
\hline \multicolumn{10}{|c|}{ Phosphate in rivers (mg P04 per litre) } \\
\hline European Union & 0,106 & 0,101 & 0,103 & 0,103 & 0,091 & 0,092 & 0,091 & 0,092 & 0,08 & 0,079 & 0,072 & 0,07 & 0,065 \\
\hline Slovakia & 0,145 & 0,156 & 0,158 & 0,171 & 0,145 & 0,115 & 0,103 & 0,112 & 0,105 & 0,103 & 0,08 & 0,078 & 0,092 \\
\hline
\end{tabular}

Source: EEA, authors' own elaboration

The share of industry and employment in the Slovak economy $(24.6 \%)$ is one of the highest in the $\mathrm{EU}(15.6 \%)$. The figure below illustrates the share of employed persons in industry and the total number of employees. In both the EU and the Slovak Republic, there was a drop in the share of employment in industry, with the EU average going down from $17.3 \%$ (2008) to $15.6 \%$ in 2018 (by 1.7 percentage points). In the Slovak Republic, the decrease was also by 1.7 percentage points (from $26.3 \%$ in 2008 to $24.6 \%$ in 2016). The average share was $15.9 \%$ in the EU and $24.2 \%$ in the SR over the past 9 years. The decline is also supported by the linear trend of EU development with a confidence level of $60 \%$. Concerning Slovakia, the confidence level is low (4 $\%)$ for the relevant data were not available in the official statistical databases. Slovakia is copying the development of the majority of EU economic indicators, therefore a decrease in the share of industry in employment in subsequent years can be expected.

According to several studies (page 12 in the Strategy), it is estimated that many traditional occupations will disappear due to automation and process optimization. Workers are at risk as robots are estimated to replace $55 \%$ of jobs in Slovakia. The most vulnerable will be those performing low-skilled jobs, particularly in industry. It will be necessary to take appropriate steps to prepare Slovakia for the future challenges in the labour market.

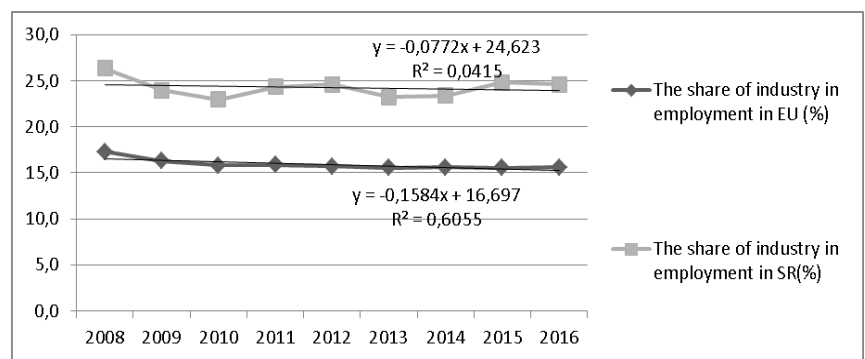

Figure 7. The Share of Industry in Employment in the SR and $\mathrm{EU}(\%)$

Source: (EUROSTAT, Authors' Own Calculations and Elaboration)

As shown in the following figure, the total number of employees in industry decreased from 638.5 thousand employees (2008) to 608.2 thousand employees in 2016. The decline was of $4.75 \%$. The average number of employees working in industry was 572.64 thousand. The number of employees increased over the last 4 years of monitored period. Yet, there was a decrease in the number of employees working in industry of 109.4 thousand in 2010 compared to 2008 due to economic crisis. Even after the recovery from the economic crisis, the number of employees never reached the previous numbers. Moreover, the linear equation of the trend line supports the downward trend in the number of employees.

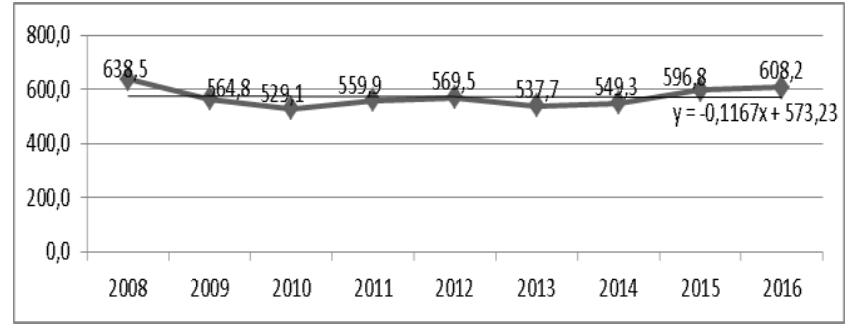

Figure 8. Employees in Industry in the Slovak Republic

(Thousand Persons)

Source: (EUROSTAT, authors' own elaboration)

The success of the Smart Industry concept depends on making the relevant subjects aware of its necessity, benefits and risks. In the light of competitiveness, Slovak science and research need to undergo changes in order to have top researchers and sufficient funding. Slovak research and science institutions are under-staffed and cannot meet the requirements related to Smart Industry. Even though the Slovak economy is growing at a fast pace, the country is far behind the European average in research and development $(R \& D)$ and innovation processes. The causes are not only insufficient funding of $R \& D$, but also a strong focus on basic research, relative isolation of Slovak research and still relatively low impact on growth of executed outputs and innovation capacity of Slovak economy (Ivanova, Kordos, 2017). The following figure lists research spending in the SR compared to other countries. Several best countries in science and research are listed, such as Japan, Sweden, Finland, Germany, the USA, and China. The Slovak Republic lags badly behind the countries listed in terms of research development spending. Research and development spending is defined as a percentage of gross domestic product. The expenditure was only $0.49 \%$ of GDP at the beginning of the monitored period in 2005. In the EU, the 
average expenditure was more than three times higher, reaching $1.74 \%$ of GDP. Sweden (3.39\%), Finland (3.33 $\%)$ and Japan $(3.18 \%)$ spent more than $3 \%$ of GDP on R\&D. Slovakia spent $0.79 \%$ of GDP on R\&D, lagging way behind the EU average ( $2.03 \%$ / by 1.24 percentage point) in the last monitored year of 2016. The total average of expenditure was $0.68 \%$ in the monitored period in Slovakia, which was far below the EU average (1.92\%). Research and development funding has long been unsatisfactory. Therefore, systemic changes in the funding of science, research and education in Slovakia are required.

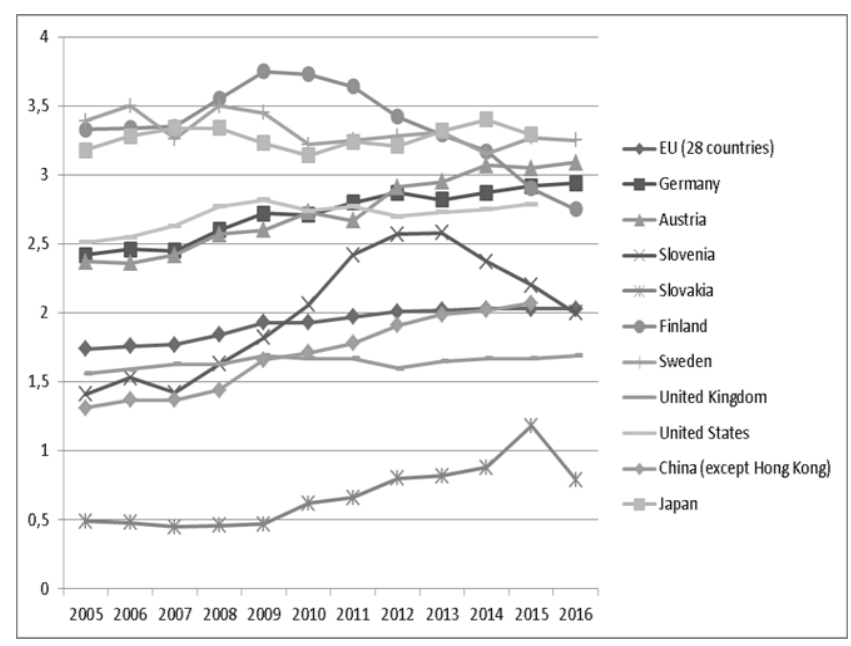

Figure 9. Expenditures on Science and Research in Selected Countries (\% of GDP)

Source: (OECD, authors' own elaboration)

Changes in education funding need to go hand in hand with research funding in the Slovak Republic. At present, schools are funded per student. That is why, many schools suffer from insufficient funding due to downward demographic trends. Another issue that needs to be addressed is the quality of teaching. In Slovakia, there is a lack of quality teachers for low salaries and unattractiveness of teaching. In the following figure, the annual average gross salaries of teachers in Slovak higher education were compared with the highest possible salary grade in selected EU countries. Luxembourg teachers have long been at the top of salary rankings, with an average yearly salary of $€$ 124,075 in 2016. The Slovak Republic has long been ranked low. The average yearly salary was $€ 17,402.4$ in 2015 . Teachers in higher education in the remaining V4 countries all have higher average yearly salaries: Czech Republic (€ 20,131), Poland (€ 23,806) and Hungary (€24,918). Much higher salaries are paid in most countries, such as for instance in Germany ( $€ 80,484$ ), Austria ( $€$ 68,420), the Netherlands ( $€ 62,341 €)$, Slovenia (€41,964.3). The effort of the Slovak government to hire university graduates to provide high quality education will certainly not help teachers to be paid at least the average EU yearly salary. Which is the lowest value in the EU $(€ 11,467)$.

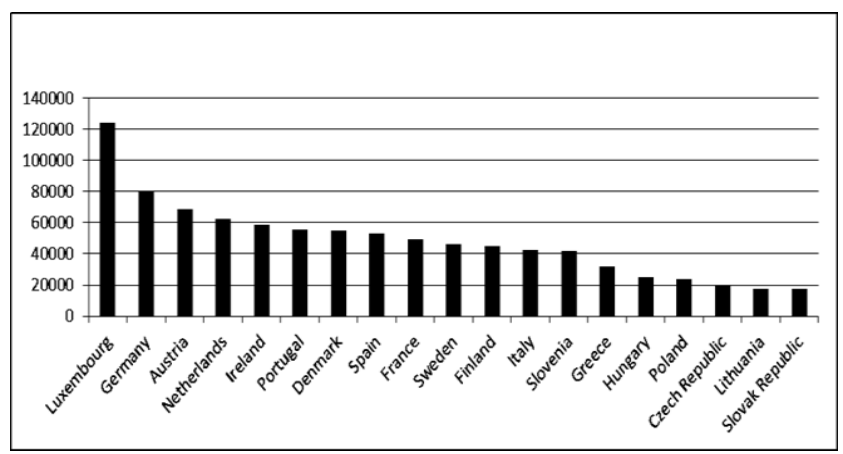

Figure 10. Average Yearly Salary $(€)$ of Educational Institutions in 2016

Source: (EUROSTAT, authors' own elaboration)

\section{Conclusions}

Special attention will be paid to the introduction of the smart industry concept in universities that are doing applied research and educate professionals for labour markets. The reform of higher education has constantly been postponed for various political reasons. Digitization will also be needed in the system of higher education, and when linked to the Big Data, one can talk about smart education. There is no point of memorizing facts, but learning how to use ICT to search for knowledge sources. Knowledge can quickly become obsolete with technology changing that fast. Intelligent industry, however, will speed up the process, so traditional learning will no longer be effective. Sustainable development is a process of change in which the exploitation of resources, investment direction, the orientation of technological development, and institutional changes are all in harmony and enhance both current and future potential to meet human needs and aspirations provided that the needs of today are met without compromising the ability of next generations to meet their own needs. (World Commission for Environment 1987). The Industry 4.0 is introducing digital technologies into manufacturing, some of which are available even today. Thus, automated manufacturing systems, big data, digital businesses, robots, and others are gradually developing smart data, smart businesses, and artificial intelligence. Industry 4.0 is both a challenge and opportunity for ensuring long-term competitiveness in a global environment. Industry 4.0 will impose new requirements for the education system and applied research while having significant impacts on the labour market, employee skills as well as many social consequences. The smart employment of tertiary education specialists in industry is growing in the advanced economies of the EU. It is obvious in the structure of both assets and employment, that the Slovak industry mainly needs low-skilled labour for manufacturing and assembly. Job creation policies should focus on the final phases of the production chain, which are characterized by high intellectual performance and high income levels. Therefore, the system of education should reflect these trends in order to make the young generation ready for changes in the labour market. The current education system in the Slovak Republic is no longer capable of preparing young people for jobs of the future workforce as was found in previous research done at our university. On the one hand, remarkable progress in innovation, digitization and communication technologies, 
and artificial intelligence have been made, but the system of education and training has not been changed fundamentally. Changes that were made were mainly organizational changes. Undoubtedly, technology is vital to education. When discussing digitization, smart businesses, or smart cities, one should also consider smart learning. We are aware now of the implications of the fourth industrial revolutions. I will bring new work organization, more interesting and challenging roles for employees, significant shift in how people work, and changes in job profiles of many occupations. Despite the known facts, no strategies have been adopted to make the education system ready respond to the new trends. In our opinion, the concept of Industry 4.0 is so challenging that it will mean the end of the traditional education system. Communication technologies will make vocational training much more effective, interactive models will be more accessible and time-saving for learners. Thus, digital and other competences will be essential for teaching. Strong emphasis will be given on searching for Big Data and developing communication skills. Artificial intelligence may also be used in education, thus both the content and form of education will be altered. There will also be major social changes. As many jobs will disappear, governments will need to provide the jobless with living wages. On the one hand, consumption will be supported, and on the other hand, many people will lose meaningfulness of life. Latest technologies along with the influx of foreign investments are essential to sustainable development and environmental sustainability. Slovakia has reduced environmental pollution. Reduced air pollution, energy efficiency, and a growth in renewable energy consumption result all from new technologies and drawings from the EU funds. It is therefore recommended to continue with the established economic and social trends. The issue of environment, however, needs to be given more attention.

Long-term sustainable development relies not only on government and international institutions, but also the business sector. Companies themselves need to understand their role in sustainable development. Many companies will have to implement new technologies into manufacturing processes. Companies cannot wait for government decisions to be taken. They must adapt to new legislative, economic and environmental conditions beforehand. The government, business sector, research and education institutions must ensure sustainable development in broad areas of social and economic life through wideranging professional discussions. Discussions must ensure the connection of sustainable development goals with the education system and the needs of the market. In this process, small and medium-sized enterprises play a central role whereas their willingness to adapt to new conditions is essential.

This study was created in the frame of the project VEGA No. 1/0430/18 "The impact of Industry 4.0 on changes in job structure".

\section{References}

Bhaduri, A., Bogard, J., Siddiq, A., Voigt, H., Vorosmarty, C., Pahl-Wostl, C., Bunn, S., Shrivastava, P., Lawford, R., Foster, S., Kremer, H., Renaud, F., Bruns, A., \& Osuna, V. (2016). Achieving sustainable development goals from a water perspective. Frontiers in Environmental Science, 4(64). https://doi.org/10.3389/fenvs.2016.00064

Bowen, K. J., Cradock-Henry, N. A., Koch, F., Patterson, J., Hayha, T., Vogt, J., \& Barbi, F. (2017). Implementing the "Sustainable Development Goals": Towards addressing three key governance challenges-collective action, tradeoffs, and accountability. Current opinion in environmental sustainability, 26, 90-96. https://doi.org/10.1016/ j.cosust.2017.05.002

Byrns, T. R., \& Stone, G. W. (1989). Economics. 4th edition. Scott, Foresman and Company, London.

Fischer, S., Dornbusch, R., \& Schmalensee, R. (1988). Economics. 2nd edition. McGraw-Hill Book Company, New York.

Gao, L., \& Bryan, B. (2017). Finding pathways to national-scale land-sector sustainability. Nature, 544, $217-222$. https://doi.org/10.1038/nature21694

Haski-Leventhal, D. (2015). Yes it is our business: how corporations can help on sustainable development goals. (Accessed 25 November 2017), Available online: https://theconversation.com/yes-it-is-our-business-howcorporations-can-help-on-sustainable-development-goals-48247

Ivanova, E., \& Kordos, M. (2017). Competitiveness and innovation performance of regions in Slovak Republic. Marketing and Management of Innovations, 1, 145-158, https://doi.org/10.21272/mmi.2017.1-13

Kanie, N., \& Biermann, F. (2017). Governing Through Goals: Sustainable Development Goals as Governance Innovation. The MIT Press, London. https://doi.org/10.7551/mitpress/10894.001.0001

Koisova, E., \& Masarova, J. (2012). Differences in the Development of Unemployment and Long-term Unemployment in Slovakia and in the Trencin region. Social and Economic Revue, 3(8), 55-65.

Koisova, E, Ivanova, E., \& Krajco, K. (2003). Zaklady ekonomickych teorii (Vybrane kapitoly). Trencianska Univerzita A. Dubceka, Trencin, Slovakia.

Kordos, M., \& Karbach, R. (2014). The Issue of Innovation in International Economics. Vocational Training and Employment in The Creative Industry. SGEM Conference on Political sciences, law, finance, economics and tourism, 3, 653-662. https://doi.org/10.5593/sgemsocial2014/B23/S7.081 
Lisy, J. (2003). Dejiny ekonomickych teorii. 3rd edition. Wolters Kluwer (Iura Edition), Bratislava.

Longo, F., Nicoletti, L., \& Padovano, A. (2017). Smart operators in industry 4.0: A human-centered approach to enhance operators' capabilities and competencies within the new smart factory context. Computers \& Industrial Engeneering, 113, 144-159. https://doi.org/10.1016/j.cie.2017.09.016

Malthus, R. T. (2017). Essay on the Principle of Population. The 1803 Edition, Yale University Press, USA.

Masarova, J. (2014). Differences in the performance of the Visegrad group regions. SGEM Conference on Political sciences, law, finance, economics and tourism, 4, 195-202. https://doi.org/10.5593/sgemsocial2014/B24/S7.025

Masarova, J. (2015). Makroekonomicke analyzy a rozhodovacie procesy. Trencianska univerzita A. Dubceka, Trencin, Slovakia.

Max-Neef, M., \& Smith, P. B. (2014). La Economia Desenmascarada. Del Poder y la codicia a la Compasion y el Bien Común. Icaria: Barcelona, Spain.

Ministry of Economy of the Slovak Republic (2017). Koncepcia inteligentneho priemyslu pre Slovensko. Bratislava. (accessed 21 November 2017) Available online: http://www.economy.gov.sk/inovacie/strategie-a-politiky/smartindustry

Ministry of Environment of the Slovak Republic (2001). Narodna strategia trvalo udržatel'neho rozvoja. Bratislava. (accessed 21 November 2017) Available online: http://www.minzp.sk/dokumenty/strategicke-dokumenty/

Navickas, V., Vojtovic, S., \& Svazas, M. (2017). Biomass clusters influence on business competiveness. In: Polish Journal of Management Studies, 2(16), 188-197. https://doi.org/10.17512/pjms.2017.16.2.16

Nilsson, M. (2017). Important Interactions under the Sustainable Development Goals under Review at the High Level Political Forum 2017. Stockholm Environment Institute, Sweden. Available online: https://mediamanager.sei.org/ documents/ Publications/SEI-WP-2017-06-Nilsson-SDG-interact-HLPF2017.pdf

Nilsson, M., Griggs, D., \& Visbeck, M. (2016). Policy: map the interactions between sustainable development goals nature. Nature, 534 (7607), 320-322. https://doi.org/10.1038/534320a

Nilsson, M., Griggs, D., Visbeck, M., \& Ringler, C. (2016). Working Paper: Draft Framework for Understanding SDG interactions. International Council for Science (ICSU), Paris. (accessed 28 November 2017). Available online: https://www.icsu.org/publications/working-paper-a-draft-framework-for-understanding-sdg-interactions-2016

Nilsson, M., Lucas, P., \& Yoshida, T. (2013). Towards an integrated framework for SDGs: ultimate and enabling goals for the case of energy. Sustainability, 5, 4124-4151. https://doi.org/10.3390/su5104124E.

Polanyi, K. (1957). The Great Transformation: The Political and Economic Origins of Our Time. Beacon Press: Boston, MA, USA.

Ricardo, D. (2004). The Principles of Political Economy and Taxation. Dover book, New York, USA.

Rojko, A. (2017). Industry 4.0 Concept: Background and Overview. International Journal of Interactive Mobile Technologies, 5 (11), 77-89. https://doi.org/10.3991/ijim.v11i5.7072

Samuelson, A. P., \& Nordhaus, D. W. (2007). Ekonomie. 18th edition. NS Svoboda, Praha, Czech Republic.

Schumpeter, J. A. (1983). Theory of Economic Development. Routledge, New York, USA.

Sileika, A., \& Andriusaitiene, D. (2006). Problems of Identifying and Regulating the Structure of the Labour Market in Depressive Lithuanian Regions. Journal of Business Economics and Management, 7 (4), $223-233$. https://doi.org/10.108 0/16111699.2006.9636143

Smith, A. (2008). Wealth of Nations. Oxford University Press, UK.

SMLC. SMLC is proudly representing Smart Manufacturing in the Smart America Challenge! 2014. (accessed 23 November 2017) Available online: https://smartmanufacturingcoalition.org/sites/default/files/smlc_smart_ america_press_release_vf_0_1.pdf

Strunz, H., \& Vojtovic, S. (2014). Vocational Training and Employment In The Creative Industry. SGEM Conference on Political sciences, law, finance, economics and tourism, 3, 787-794. WOS:000359614800098

Vojtovic, S., \& Krajnakova, E. (2013). Trends in Economic Growth and Unemployment in Slovakia. Proceedings of the 2013 International Conference on Education, Management and Social Science (ICEMSS-13), 188-191. https://doi.org/10.2991/icemss.2013.51

World Economic Forum. (2016). The Future of Jobs, Employment, Skills and Workforce Strategy for the Fourth Industrial Revolution. World Economic Forum, Geneva, Switzerland.

The article has been reviewed.

Received in May 2018; accepted in February 2019. 